\title{
Which treatments are most effective for common tendinopathies? A systematic review and network meta-analysis protocol.
}

\author{
Swinton, P.A. ${ }^{*}$ Shim, J. ${ }^{1}$ Pavlova, A.V. ${ }^{1}$ Moss, R.A. ${ }^{1}$ Maclean, C. ${ }^{2}$ Brandie, D. ${ }^{3}$ Mitchell, L. ${ }^{4}$ Greig, L. ${ }^{1}$ \\ Parkinson, E. ${ }^{1}$ Morrissey, D. ${ }^{5}$ Alexander, L. ${ }^{1}$ Cooper, K. ${ }^{1}$
}

\section{$10.31236 /$ osf.io/mx5pv}

SportR $\chi$ iv hosted preprint version 1

$20 / 05 / 2021$

PREPRINT - NOT PEER REVIEWED

\section{Institutions}

${ }^{1}$ School of Health Sciences, Robert Gordon University, Aberdeen, UK

${ }^{2}$ Library Services, Robert Gordon University, Aberdeen, UK

${ }^{3}$ Sport Scotland, Inverness, UK

${ }^{4}$ NHS Grampian, Aberdeen, UK

${ }^{5}$ Centre for Sports \& Exercise Medicine, Barts \& the London School of Medicine \& Dentistry, London, UK

* Corresponding Author

Dr. Paul Swinton

School of Health Sciences, Robert Gordon University

Garthdee Road

Aberdeen, UK,

AB10 7QG

p.swinton@rgu.ac.uk, +44 (0) 12242623361

\section{Funding}

This project is funded by the National Institute for Health Research (NIHR) [Health Technology Assessment (HTA) 129388 Exercise therapy for the treatment of tendinopathies]. The views expressed are those of the authors and not necessarily those of the NIHR or the Department of Health and Social Care.

\section{Conflicts of interest}

The authors declare no conflict of interest. 


\subsection{Introduction}

Tendinopathy is a common musculoskeletal condition associated with degenerative changes within a tendon affecting both athletic and non-athletic populations. ${ }^{1}$ The condition is characterized by a combination of pain, ${ }^{1}$ and impaired movement ${ }^{2}$ and function ${ }^{3}$, requiring extended periods for recovery.,2,-5 Tendinopathy can affect any muscle-tendon unit in the body, ${ }^{6}$ however, it is most frequently reported in the Achilles, patellar, lateral elbow, rotator cuff, and hip tendons. ${ }^{6}$ Surveys of prevalence of lower extremity tendinopathy in the general population have reported rates of 11.8 and 10.5 per 1000 person-years, ${ }^{7}$ whilst prevalence for upper limb tendinopathies have been estimated between $1.3 \%$ to $21.0 \% .{ }^{8-10}$ Tendinopathies can affect children, adolescents, and adults of all ages, and many tendinopathies have a chronic or recurrent course. ${ }^{6}$ Costs to the individual, the health service and economy (due to absenteeism and loss of productivity) are substantial such that identifying effective interventions is a priority. Musculoskeletal conditions including tendinopathies also have a substantive influence on primary and secondary healthcare use. ${ }^{11}$ By identifying effective interventions across a range of tendinopathies, General Practitioners and other first-contact practitioners (e.g. physiotherapists) can be confident in delivering effective evidence-based practice. With an ageing population, and increasing pressure and demands on healthcare services, the need for clear guidance for evidence-based practice has never been more important.

The clinical management of symptomatic tendinopathy requires complex clinical reasoning with reference to the pathoanatomical diagnosis. Rehabilitation strategies can vary substantively depending on the site, stage of the tendinopathy, functional baseline, contributing issues within the kinetic chain, and patient factors including activity level, comorbidities, and coexisting presentations. ${ }^{12}$ Current research supports the role of appropriate loading in strength training as the primary treatment of tendinopathy. ${ }^{13}$ Different principles of loading such as eccentric loading, combined loading, and heavy, slow resistance training (HSRT) have each been recommended with similar goals to initiate tendon adaptations and restore function. However, observable structural change does not always correlate with positive therapeutic outcomes. Most tendinopathies have associated movement dysfunction which may require movement retraining or motor control-based exercises to retrain normal patterns of muscle recruitment. There is also evidence to suggest the role of potential corticospinal involvement or central sensitisation resulting from persistent pain particularly in chronic tendinopathy. Given the complexities involved, treatments may comprise multiple therapy modes with exercise frequently used as an adjunct with ultrasound, extracorporeal shockwave, laser therapy, or following regenerative or ortho-biologic procedures such as prolotherapy, platelet-rich plasma or stem-cell therapies. ${ }^{14}$ Additionally, for those with refractory symptoms, surgical interventions may be indicated.

Currently, the best therapy for tendinopathy remains uncertain. Previous systematic reviews have generally focused on single tendinopathies and resorted to qualitative syntheses of evidence due to concerns of both statistical and clinical heterogeneity. Where, meta-analyses have been conducted, these have generally focussed on small numbers of homogenous studies employing conventional pairwise approaches that do not offer comparative effectiveness of the wide range of treatments, leading to a lack of established hierarchy in tendinopathy interventions. More recent perspectives in evidence synthesis highlight that with complex 
interventions statistical heterogeneity should be expected and as is the case with primary data, variance presents opportunities for informative explanatory analyses. ${ }^{15}$ Currently a range of approaches have been developed to best synthesise complex and heterogenous data, with statistical approaches including the use of network metaanalyses (NMA) that can potentially be combined with meta-regression. ${ }^{15}$ Recent NMAs investigating tendinopathy treatments have focused on localised site-specific tendons with pain relief and function as the predominant outcomes. ${ }^{16-20}$ Four NMAs have investigated comparative effectiveness of treatments in upper extremity tendinopathies, three of which studied injection therapies in the shoulder ${ }^{17}$ or elbow ${ }^{18,19}$ while one other focused on non-surgical treatments for chronic calcific tendinitis of the shoulder. ${ }^{16}$ In a NMA of nonsurgical treatments for patellar tendinopathy of 11 trials, Chen et al. ${ }^{20}$ concluded that platelet-rich plasma has the greatest improvements in pain and function compared with other treatment options. However, the review excluded studies that compared different types of exercise therapy from their analysis. Two recent NMAs assessing the effectiveness of evidence-based treatment for adults with Achilles tendinopathy reported somewhat conflicting findings. The review of 29 RCTs by van der Vlist et al. ${ }^{21}$ concluded there was strong evidence that all active treatments were superior to wait-and-see, but no one active treatment could be recommended over another. In contrast, Rhim et al. ${ }^{22}$ suggested that high-volume injection with corticosteroid and extracorporeal shockwave therapy may be combined with eccentric exercise to produce sustained benefits in Achilles tendinopathy. However, these latter results were based on a small sample size of two pooled studies. All previous NMAs investigating tendinopathy treatments have reported substantive statistical heterogeneity but have not included sufficient data to explore the variance and thereby generate additional relevant clinical findings. Therefore, the purpose of the present systematic review and NMA is to compare the effectiveness of different treatment classes across a range of tendinopathies and outcomes to better establish a treatment hierarchy. Where sufficient data are obtained, the potential for covariates including patient demographics and condition specifics (e.g. symptom severity) to explain statistical heterogeneity will be explored.

\subsection{Inclusion criteria}

This review is part of a project funded by the National Institute for Health Research (NIHR); Health Technology Assessment (HTA) 129388 Exercise therapy for the treatment of tendinopathies. The inclusion criteria are influenced by the project aims, the results of our initial scoping review mapping the exercise and tendinopathy literature ${ }^{14}$ as well as stakeholder workshops.

\section{Participants}

This review will include people of any age or gender with a diagnosis of tendinopathy of any severity or duration and at any anatomical location. Studies that include participants with tendinopathy in the absence of full thickness or large tears, will be included. Groups where the tear size cannot be determined will also be excluded as these require different management approaches. We will accept trial authors' diagnoses where a clearly verifiable group of clinical features is reported including: pathognomonic location of pain; a symptom altering response to applied load and/or stretch, with there being a specific test for most tendinopathies; strategies to rule out differential diagnoses; ultrasound or magnetic resonance imaging confirmation of structural change. Studies with mixed 
groups will have data included where there is clear reporting of the tendinopathic group, or they make up $>90 \%$ of the investigated cohort. Our definition of tendinopathy therefore includes tendinopathies such as PTTD (posterior tibial tendon dysfunction), tibialis posterior tendinopathy, peroneal tendinopathy, and GTPS (greater trochanteric pain syndrome). However, it excludes plantar heel pain as this condition may respond differently to exercise therapy and could potentially confound the review findings.

\section{Intervention}

The primary health technology being assessed is exercise therapy for the treatment of any tendinopathy. Exercise therapies considered for inclusion will comprise five treatment classes: 1) resistance; 2) plyometric; 3) vibration; 4) flexibility and 5) movement pattern retraining modalities (see appendix I for definitions). Exercise therapy may be delivered in a range of settings (e.g. primary care, secondary care, community, people's homes) by a range of health or exercise professionals (e.g. physiotherapists, strength \& conditioning coaches, personal trainers) or support workers, and may be supervised or unsupervised (i.e. self-management). No restrictions will be placed on these factors for inclusion.

To be included in the review, studies are required to report sufficient information regarding the exercise intervention to enable appropriate identification of treatment class and quantification of exercise dose. In clinical settings it has been recommended that exercise dose is determined by duration, frequency, and intensity; where duration reflects the amount of time accrued in a single exercise session, frequency captures the number of exercise sessions over periods such as a week, and exercise intensity is defined either in absolute terms (such as the metabolic cost of an exercise session), or in relative terms (such as the performance of a given activity as a function of some percentage of measurable maximum capacity. To be included in the review, studies are required to provide sufficient information to describe at least two of the three parameters describing exercise dose. Where sufficient information is not presented in the main text of a study, a search will be made of the publishers' website to check for supplementary files that may include relevant information.

\section{Comparator}

The review will include studies that compare exercise therapies with non-active therapies (placebo or no intervention), other conservative therapies or surgery. Definitions of broad and specific treatment classes for the different therapy types are provided in appendix I.

Outcomes

Based on the results of our initial scoping review and subsequent stake holder workshops we will include outcomes that assess ten domains: 1) Disability; 2) Physical function capacity; 3) Pain on loading/activity; 4) Pain over a specified time; 5) Pain without further specification 6) Participant/patient rating overall condition; 7) Participation; 8) Quality of life; 9) Adverse effects/events; and 10) Range of motion (for studies investigating rotator cuff tendinopathy only). Definitions for each domain and example measurement tools are presented in appendix II.

\section{Types of studies}

We will include randomized controlled trials and non-randomized controlled trials. 
Context

The context will include primary care, secondary care or community locations in any developed nation (defined as the top 62 countries in the Human Development Index at the time of protocol development $)^{23}$ for the findings to be relevant to the UK context.

\subsection{Exclusion criteria}

We will exclude self-described pilot studies and non-intervention studies where the purpose of the research is to investigate the acute effects of exercise on physiological or biomechanical variables such as pain, collagen turnover or mechanical properties of tendons.

\subsection{Methods}

The review will be conducted according to the PRISMA extension statement for reporting of systematic reviews incorporating NMAs of health care interventions ${ }^{24}$ and the recent GRADE approach to drawing conclusions from NMA using a minimally contextualised framework. ${ }^{25}$

\section{Search strategy}

The search strategy used for this study was part of a larger search conducted to scope the entire tendinopathy and exercise therapy research base. The search comprised three steps; Firstly, a limited search of MEDLINE and CINAHL using initial keywords (MH tendinopathy OR TX tendin* OR TX tendon*) AND (MH exercise OR TX exercis*) was conducted with analysis of the text words in the titles/abstracts and those used to describe articles to develop a full search strategy. Secondly, the full search strategy was adapted to each database and applied systematically to: MEDLINE, CINAHL, AMED, EMBase, SPORTDiscus, Cochrane library (Controlled trials, Systematic reviews), JBI Evidence Synthesis, PEDRo, and Epistemonikos (a full search strategy for MEDLINE is presented in appendix III). The following trial registries were also searched: ClinicalTrials.gov, ISRCTN Registry, The Research Registry, EU-CTR (European Union Clinical trials Registry), ANZCTR (Australia and New Zealand Clinical trials Registry). Finally, the third step involved conducting a search of cited and citing articles using Scopus and hand-searching a total of 130 systematic reviews that were identified to include information relevant to exercise therapy and tendinopathy. No limit was placed on language, with research studies published in languages other than English translated via Google Translate or via international collaborations of the review team members. Searches were initiated from 1998 as (i) the heavy load eccentric calf-training protocol for Achilles tendinosis by Alfredsson et al ${ }^{26}$ was published in 1998 and may be considered seminal work in the field of tendinopathy, and (ii) there has been a proliferation of research on exercise interventions for tendinopathies post 1998.

Study selection 
Proquest ${ }^{\circledR}$ Refworks will be used to manage references and remove duplicates, before importing to Covidence (Melbourne, Australia) to facilitate screening. Two levels of screening will be conducted. First all titles/abstracts will be reviewed, independently, by two members of the research team. Conflicts will be resolved by discussion or by input from a third reviewer. Full-text copies of all studies included at title/abstract screening stage will be retrieved and these will also be screened independently by two members of the research team with conflicts resolved in the same way.

Data extraction

Data will be extracted independently by 8 members of the review team (PS/KC/LA/RM/LG/EP/JS/AP) into pre-piloted excel sheets. Data will be independently coded as described in the accompanying codebook (appendix IV). To quantify reliability, 10\% of studies will be selected at random and extraction completed in duplicate. Reliability will be quantified using Cohens $\mathrm{K}$ statistic ${ }^{27}$ for categorical variables and percentage agreement for continuous variables.

Risk of bias assessment

We will use the Cochrane Collaboration's Risk of Bias tool ${ }^{28}$ and all five domains: 1) selection bias; 2) performance bias; 3) detection bias; 4) attrition bias; and 5) reporting bias, to assess risk of bias for all included RCTs. For non-random designs, we will use the ROBINS-I tool ${ }^{29}$ and all seven domains: 1) bias due to confounding; 2) bias in selection of participants into the study; 3) bias in classification of interventions; 4) bias due to deviations form intended interventions; and 5) bias due to missing data; 6) bias in measurement of outcomes; and 7) bias in selection of the reported. An overall risk of bias judgement will be made for each outcome and time point as either 'low risk', 'some concerns' or 'high risk' of bias. A single assessment will be made by a reviewer from the team with comments saved to justify selection for each signalling question. To quantify reliability, $10 \%$ of studies will be selected at random and extraction completed in duplicate.

\section{Statistical analysis}

We will fit treatment class (broad and specific) Bayesian models. Pairwise effect sizes will be calculated with standardised mean differences ( $\left.\mathrm{SMD}_{\mathrm{pre}}\right)$ for continuous outcomes and proportional odds models used for binary outcomes. Initially, direct pair-wise comparisons will be estimated. We will then combine direct and indirect comparisons using NMA and hierarchical NMA if possible. ${ }^{30}$ Outcomes will be analysed separately according to short ( $\leq 12$ weeks), medium (13-52 weeks) and long ( $>52)$ time frames. Following the GRADE approach for presentation and interpretation of results, we will select a reference intervention defined as the most connected node in the network. To maintain a minimally contextualised framework, we will select a no effect threshold and move any treatment or treatment class above or below the reference if $95 \%$ credible intervals do not span the threshold. Second classifications will then be made based on comparisons with treatment classes moved relative to the reference. In each of the classifications, treatment classes will be separated into: 1) moderate to high certainty; and 2) low to very low certainty based on risk of bias, inconsistency and indirectness. ${ }^{31}$ Inconsistency will be assessed using model-based methods and comparison of residual deviance and the deviance information criterion). ${ }^{32}$ Finally, consistency of the treatment and treatment class hierarchies created in previous steps will be 
10.31236/osf.io/mx5pv | SportsR $x$ iv Preprint version 1

assessed by examining pairwise comparisons not previously used. Sources of statistical heterogeneity will only be explored in cases where there are 10 or more trials available per comparison. ${ }^{21}$ 


\section{References}

1. Hopkins C, Fu SC, Chua E, Hu X, Rolf C, Mattila VM, et al. Critical review on the socio-economic impact of tendinopathy. Asia Pac J Sports Med Arthrosc Rehabil Technol. 2016; 4: 9-20.

2. Lewis J. Rotator cuff related shoulder pain: Assessment, management and uncertainties. Man Ther. 2016; 23:57-68.

3. Alizadehkhaiyat O, Fisher AC, Kemp GJ. Pain, functional disability and psychologic status in tennis elbow. Clin J Pain. 2007; 23(6): 482-489.

4. Seil R, Litzenburger H, Kohn D. Arthroscopic treatment of chronically painful calcifying tendinitis of the supraspinatus tendon. Arthroscopy. 2006; 22(5): 521-527.

5. Comin J, Malliaras P, Baquie P, Barbour T, Connell D. Return to competitive play after hamstring injuries involving disruption of the central tendon. Am J Sports Med. 2013; 41(1): 111-115.

6. Fu FH, Wang JH-C, Rothrauff BB. BMJ Best Practice Tendinopathy [Internet]. London: BMJ; 2019 [cited 2019 Jul 20]. Available from:

https://bestpractice.bmj.com/topics/en-gb/582

7. Albers IS, Zwerver J, Diercks RL, Dekker JH, Van den Akker-Scheek I. Incidence and prevalence of lower extremity tendinopathy in a Dutch general practice population: a cross sectional study. BMC Musculoskelet Disord. 2016; 17:16.

8. Littlewood C, May S, Walters S. Epidemiology of Rotator Cuff Tendinopathy: A Systematic Review. Shoulder \& Elbow. 2013; 5(4): 256-265.

9. Shiri R, Viikari-Juntura E, Varonen H, Heliövaara M. Prevalence and determinants of lateral and medial epicondylitis: A population study. Am J Epidemiol. 2006; 164(11): 1065-1074.

10. Vos T. Years lived with disability (ylds) for 1160 sequelae of 289 diseases and injuries 1990-2010: a systematic analysis for the global burden of disease study 2010. Lancet. 2012; 380(9859):2163-2196.

11. Kinge JM, Knudsen AK, Skirbekk V, Vollset SE. Musculoskeletal disorders in Norway: prevalence of chronicity and use of primary and specialist health care services. BMC Musculoskelet Disord. 2015;16(1):75.

12. Scott et al. Sports and exercise-related tendinopathies: A review of selected topical issues by participants of the second International Scientific Tendinopathy Symposium (ISTS) Vancouver 2012. Br J Sports Med. 2013; 47(9): 536544.

13. Magnusson PS, Langberg H, Kjaer M. The pathogenesis of tendinopathy: Balancing the response to loading. Nat Rev Rheumatol. 2010; 6(5): 262-268.

14. Alexander et al. Exercise therapy for the treatment of tendinopathies: A scoping review protocol. JBI Evid Synth. 2021; doi: 10.11124/JBIES-20-00175.
15. Lorenc et al. Meta-analysis, complexity, and heterogeneity: A qualitative interview study of researchers' methodological values and practices. Syst Rev. 2016; 5(1): 192.

16. Wu Y, Tsai W, Tu Y, Yu T. Comparative effectiveness of nonoperative treatments for chronic calcific tendinitis of the shoulder: A systematic review and network metaanalysis of randomized controlled trials. Arch Phys Med Rehabil. 2017; 98(8): 1678-1692.

17. Lin et al. Comparative effectiveness of injection therapies in rotator cuff tendinopathy: A systematic review, pairwise and network meta-analysis of randomized controlled trials. Arch Phys Med Rehabil. 2019; 100(2): 336-349.

18. Dong et al. Injection therapies for lateral epicondylagia: A systematic review and Bayesian network meta-analysis. Br J Sports Med. 2016; 50(15): 900-908.

19. Krogh et al. Comparative effectiveness of injection therapies in lateral epicondylitis: A systematic review and network meta-analysis of randomized controlled trials. Am J Sports Med. 2013; 41(6): 1435-1446.

20. Chen et al. Comparative effectiveness of different nonsurgical treatments for patellar tendinopathy: A systematic review and network meta-analysis. Arthroscopy. 2019; 35(11): 3117-3131

21. van der Vlist et al. Which treatment is most effective for patients with Achilles tendinopathy? A living systematic review with network meta-analysis of 29 randomised controlled trials. Br J Sports Med. 2021; 55(5): 249-256.

22. Rhim HC, Kim MS, Choi S, Tenforde AS. Comparative efficacy and tolerability of nonsurgical therapies for the treatment of midportion Achilles tendinopathy. A systematic review with network meta-analysis. Orthop J Sports Med. 2020; 8(7): 2325967120930567.

23. United Nations Development Programme-Human Development Reports. Human development index: Table 1 human development index and its components 2020; Retrieved from: http://hdrundporg/en/composite/HDI.

24. Hutton et al. The PRISMA extension statement for reporting of systematic reviews incorporating network meta-analyses of health care interventions: Checklists and explanations. Ann Intern Med. 2015; 26(11): 777-784.

25. Brignardello-Petersen et al. Grade approach to drawing conclusions from a network meta-analysis using a minimally contextualised framework. BMJ. 2020; 371:m3900.

26. Alfredson H, Pietilä T, Jonsson P, Lorentzon R. Heavyload eccentric calf muscle training for the treatment of chronic Achilles tendinosis. Am J Sports Med. 1998; 26(3): 360-366. 
27. Cohen J. Weighted kappa: nominal scale agreement with provision for scaled disagreement or partial credit. Psychol Bull. 1968; 70: 213-220.

28. Higgins et al. The Cochrane Collaboration's tool for assessing risk of bias in randomised trials. BMJ. 2011; 343:d5928.

29. Sterne et al. ROBINS-I: A tool for assessing risk of bias in non-randomised studies of interventions. BMJ. 2016; 355:i4919.
30. Owen RK, Tincello DG, Keith RA. Network metaanalysis: development of a three-level hierarchical modelling approach incorporating dose-related constraints. Value Health. 2015; 18(1): 116-126.

31. Guyatt et al. GRADE: An emerging consensus on rating quality of evidence and strength of recommendations. BMJ. 2008; 336:924.

32. Dias et al. Evidence synthesis for decision making 4: Inconsistency in networks of evidence based on randomized controlled trials. Med Decis Making. 2013; 33(5): 641-656. 
Appendix I: Definitions use to define broad and specific treatment classes.

\begin{tabular}{|c|c|c|c|}
\hline $\begin{array}{l}\text { Broad } \\
\text { Treatment } \\
\text { Class }\end{array}$ & Definition & Specific Treatment Class & Definition \\
\hline \multirow{5}{*}{ Exercise } & \multirow{5}{*}{$\begin{array}{l}\text { Exercise therapy is } \\
\text { defined as a regimen or } \\
\text { program of physical } \\
\text { activities specifically } \\
\text { designed and prescribed } \\
\text { to correct impairments, } \\
\text { restore musculoskeletal } \\
\text { function, and/or } \\
\text { maintain a state of } \\
\text { wellbeing. }\end{array}$} & Resistance & $\begin{array}{l}\text { Exercise designed primarily to increase strength of } \\
\text { muscles by causing them to produce substantive force } \\
\text { against an applied resistance which can take several } \\
\text { forms including the mass of the body or its segments, } \\
\text { isoinertial resistance, elastic resistance, or strength } \\
\text { training equipment such as isokinetic devices. In } \\
\text { tendinopathy, the stimulus may also be intended to } \\
\text { provoke tendon remodelling, reduce pain and } \\
\text { improve function. }\end{array}$ \\
\hline & & Flexibility & $\begin{array}{l}\text { Exercise designed to increase joint range of motion } \\
\text { and extensibility of muscles and/or associated tissues. } \\
\text { Also referred to as range-of-motion exercises or } \\
\text { stretching. }\end{array}$ \\
\hline & & Proprioception & $\begin{array}{l}\text { Exercise designed to enhance the sensation of the } \\
\text { joint relative to body position and movement, sense } \\
\text { of force, and to encourage muscular stabilisation of } \\
\text { the joint in the absence of external stabilising devices } \\
\text { e.g. ankle brace. }\end{array}$ \\
\hline & & Plyometric & $\begin{array}{l}\text { Exercise where a resistance is overcome by a muscle } \\
\text { rapidly stretching then shortening }\end{array}$ \\
\hline & & Vibration & $\begin{array}{l}\text { Exercise where body segments are held stationary or } \\
\text { actively displaced as per definitions for other } \\
\text { treatment classes whilst applying a rapid oscillating } \\
\text { resistance }\end{array}$ \\
\hline $\begin{array}{l}\text { Non-active } \\
\text { (placebo, sham, } \\
\text { wait and see) }\end{array}$ & $\begin{array}{l}\text { Includes any appropriate } \\
\text { inactive treatment such } \\
\text { as waiting list control, } \\
\text { sham shockwave, sham } \\
\text { laser, sham taping or } \\
\text { true placebo. }\end{array}$ & $\begin{array}{l}\text { Non-active (placebo, sham, } \\
\text { wait and see) }\end{array}$ & $\begin{array}{l}\text { Includes any appropriate inactive treatment such as } \\
\text { waiting list control, sham shockwave, sham laser, } \\
\text { sham taping or true placebo. }\end{array}$ \\
\hline \multirow{2}{*}{ Electro-therapy } & \multirow{2}{*}{$\begin{array}{l}\text { Modality that delivers } \\
\text { therapeutic levels of } \\
\text { physical energy into a } \\
\text { biologic system e.g. soft } \\
\text { tissue. }\end{array}$} & Shockwave & $\begin{array}{l}\text { Extracorporeal shockwave therapy (radial of } \\
\text { focussed) }\end{array}$ \\
\hline & & Laser & Low level laser therapy \\
\hline
\end{tabular}




\begin{tabular}{|c|c|c|c|}
\hline & & Other & $\begin{array}{l}\text { Other less common electro-therapies such as } \\
\text { ultrasound, radar and diadynamic current. }\end{array}$ \\
\hline \multirow{2}{*}{ Biomechanics } & \multirow{2}{*}{$\begin{array}{l}\text { Treatment using external } \\
\text { devices that alters the } \\
\text { kinematics/kinetics of } \\
\text { the limb. }\end{array}$} & Immobilisation & $\begin{array}{l}\text { Any intervention that prevents specific features of } \\
\text { joint movement e.g. splinting }\end{array}$ \\
\hline & & Altered loading & $\begin{array}{l}\text { Any intervention aimed at altering tendon loading e.g. } \\
\text { taping, tennis elbow clasp/brace and orthotics. }\end{array}$ \\
\hline Manual Therapy & $\begin{array}{l}\text { Manual therapy is the } \\
\text { skilled application of } \\
\text { "hands-on" techniques } \\
\text { to treat soft tissues and } \\
\text { joint structures for the } \\
\text { purpose of improving } \\
\text { pain, increasing range of } \\
\text { motion, stimulating } \\
\text { tissue repair response, } \\
\text { and/or improving } \\
\text { function. }\end{array}$ & Manual Therapy & $\begin{array}{l}\text { Manual therapy is the skilled application of "hands- } \\
\text { on" techniques to treat soft tissues and joint } \\
\text { structures for the purpose of improving pain, } \\
\text { increasing range of motion, stimulating tissue repair } \\
\text { response, and/or improving function. }\end{array}$ \\
\hline \multirow{3}{*}{$\begin{array}{l}\text { Injection } \\
\text { Therapy }\end{array}$} & \multirow{3}{*}{$\begin{array}{l}\text { Injection therapy for } \\
\text { tendinopathy typically } \\
\text { involves direct } \\
\text { administration of a } \\
\text { pharmacologically active } \\
\text { drug, or combination of } \\
\text { drugs using a syringe and } \\
\text { needle or equivalent. It } \\
\text { may or may not be } \\
\text { image-guided. }\end{array}$} & Autologous & $\begin{array}{l}\text { An autologous injection is an injection of a substance } \\
\text { drawn from the patient to whom it is then given, } \\
\text { usually at the tendinopathy site after content } \\
\text { manipulation with the purpose of stimulating tissue } \\
\text { healing. }\end{array}$ \\
\hline & & Drug & $\begin{array}{l}\text { An injection of a classified drug, often mixed with } \\
\text { another drug (e.g. corticosteroid with local } \\
\text { anaesthetic) for the purpose of reducing pain and } \\
\text { stimulating tissue healing. }\end{array}$ \\
\hline & & Volumetric & $\begin{array}{l}\text { An injection deliberately constructed to administer a } \\
\text { large volume of fluid to exert a mechanical, as well as } \\
\text { pharmacological, effect on the tissues to reduce pain, } \\
\text { promote tissue healing and mobilise adherent tissue. }\end{array}$ \\
\hline \multirow{2}{*}{ Surgery } & \multirow{2}{*}{$\begin{array}{l}\text { Any relevant surgical } \\
\text { intervention for } \\
\text { tendinopathy }\end{array}$} & $\begin{array}{l}\text { Minimally invasive } \\
\text { peritendinous }\end{array}$ & $\begin{array}{l}\text { Minimally invasive procedure with small portals and } \\
\text { insertion of surgical tools in the peritendinous area. }\end{array}$ \\
\hline & & Open intra-tendinous & $\begin{array}{l}\text { A more traditional open approach where the tendon } \\
\text { is exposed and the peri-tendinous and intra-tendinous } \\
\text { areas surgically treated. }\end{array}$ \\
\hline
\end{tabular}




\section{Appendix II: Outcome domains and example outcomes included in review.}

\begin{tabular}{|c|c|c|}
\hline Domain & ICON Definition & Example Tools \\
\hline Disability & $\begin{array}{l}\text { Composite scores of a mix of patient- } \\
\text { rated pain \& disability due to the pain, } \\
\text { usually relating to tendon-specific } \\
\text { activities/tasks }\end{array}$ & $\begin{array}{l}\text { VISA scales; DASH; quick DASH; SPADI; Patient-rated tennis- } \\
\text { elbow evaluation questionnaire; Constant Murley Score; WORC } \\
\text { (Western Ontario Rotator Cuff Index); AOFAS (American } \\
\text { Orthopaedic Foot \& Ankle Society); Roles and Maudsley score; } \\
\text { ASES (American Shoulder \& Elbow Surgeons Index; Tegner } \\
\text { activity score; Lysholm knee scale; Pain free function questionnaire; } \\
\text { Ankle activity score; Subjective elbow Value (SEV); Placzek score; } \\
\text { Shoulder disability questionnaire; International Knee } \\
\text { Documentation Committee form (IKDC); Penn Shoulder score } \\
\text { (university of Pennsylvania shoulder score) (PSS); Brief pain } \\
\text { inventory (BPI); UCLA Shoulder Rating Scale; FILLA - functional } \\
\text { index of leg and lower limb; Neer Shoulder Score; Nirschl phase } \\
\text { rating scale; American Shoulder and Elbow Surgeon's (MASES) } \\
\text { questionnaire; Mayo Elbow Performance Score (MEPS); Shoulder } \\
\text { rating questionnaire (SRQ) }\end{array}$ \\
\hline $\begin{array}{l}\text { Pain over a specified } \\
\text { time }\end{array}$ & $\begin{array}{l}\text { Patient-reported pain intensity over } \\
\text { period of time e.g. morning/night/24- } \\
\text { hours/1-week }\end{array}$ & VAS; NRS Painful days in 3 months \\
\hline $\begin{array}{l}\text { Pain without further } \\
\text { specification }\end{array}$ & $\begin{array}{l}\text { Patient asked about pain levels without } \\
\text { reference to activity or timeframe }\end{array}$ & VAS; NRS; Borg CR10 Scale; Pain status \\
\hline $\begin{array}{l}\text { Physical function } \\
\text { capacity }\end{array}$ & $\begin{array}{l}\text { Quantitative measures of physical tasks } \\
\text { (e.g. hops, times walk, single leg squat) } \\
\text { includes muscle strength }\end{array}$ & $\begin{array}{l}\text { Counter movement jump; One-leg triple hop; Single-leg decline } \\
\text { squat; Muscle strength measured by dynamometry (hand-held, } \\
\text { isokinetic); Repetition maximum; Manual muscle testing. }\end{array}$ \\
\hline $\begin{array}{l}\text { Patient rating overall } \\
\text { condition }\end{array}$ & $\begin{array}{l}\text { Single-assessment numerical evaluation } \\
\text { of symptom status }\end{array}$ & $\begin{array}{l}\text { Global impression/rating of change; patient-acceptable symptom } \\
\text { status/state }\end{array}$ \\
\hline Quality of Life & General wellbeing & $\begin{array}{l}\text { EQ5D; EQ3D; SF-36 or SF-12; Assessment of Quality of Life } \\
\text { (AQoL); Nottingham Health Profile; Gothenburg QoL Instrument }\end{array}$ \\
\hline Adverse effects/events & $\begin{array}{l}\text { Unwanted unintended effects of } \\
\text { treatments }\end{array}$ & Adverse event reporting \\
\hline $\begin{array}{l}\text { Range of Motion } \\
\text { (Shoulder only) }\end{array}$ & $\begin{array}{l}\text { Active or passive range of motion in } \\
\text { specified plane, measured in degrees. }\end{array}$ & Hand-held goniometer; inclinometer \\
\hline
\end{tabular}


10.31236/osf.io/mx5pv | SportsR $x$ iv Preprint version 1

\section{Appendix III: Search strategy}

MEDLINE (EBSCoHost)

Search conducted on 27 April, 2020

\begin{tabular}{|l|l|l|}
\hline Search & Query & $\begin{array}{l}\text { Records } \\
\text { retrieved }\end{array}$ \\
\hline$\# 1$ & $\begin{array}{l}\text { MH exercise OR AB exercis* OR MH “isometric contraction” OR MH rehabilitation OR TX } \\
\text { eccentric OR TX concentric OR TX “heavy slow resistance” OR TX isokinetic }\end{array}$ & 362,722 \\
\hline$\# 2$ & $\begin{array}{l}\text { MH tendinopathy OR MH “shoulder injuries" OR MH tendons OR MH “tendon injuries” OR } \\
\text { TX tendin* OR TX tendon* OR MH bursitis OR AB bursitis OR MH “posterior tibial tendon } \\
\text { dysfunction" OR MH “shoulder impingement syndrome” OR AB “greater trochanteric pain } \\
\text { syndrome" }\end{array}$ & 96,490 \\
\hline$\# 3$ & $\# 1$ AND \#2 & 4,363 \\
\hline Limited to 1998 to present & \\
\hline
\end{tabular}




\section{Appendix IV: Extraction codebook}

\begin{tabular}{|c|c|c|c|}
\hline \multicolumn{2}{|c|}{ Column } & \multirow{2}{*}{$\begin{array}{l}\text { Heading } \\
\text { Initials Reviewer }\end{array}$} & \multirow{2}{*}{$\begin{array}{c}\text { Description } \\
\text { Identification of individual extracting information }\end{array}$} \\
\hline \multirow{23}{*}{ 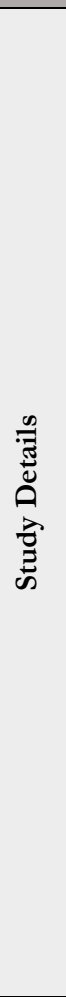 } & A & & \\
\hline & $\mathrm{B}$ & Covidence Identifier & Reference number for Covidence \\
\hline & $\mathrm{C}$ & Author & First author surname et al., \\
\hline & $\mathrm{D}$ & Year & Year of publication \\
\hline & $\mathrm{E}$ & Title & Study title \\
\hline & $\mathrm{F}$ & Country & Country where study was conducted \\
\hline & G & Journal & Journal name \\
\hline & $\mathrm{H}$ & Aims/Purpose & Study aims/purpose \\
\hline & $\mathrm{I}$ & Tendinopathy type & $1=$ Achilles; $2=$ Lateral elbow (tennis); $3=$ Patellar; $4=$ Rotator cuff (SI) \\
\hline & $\mathrm{J}$ & Study Design & $\mathrm{RCT}=1 ;$ Quasi-experimental $=2$ \\
\hline & $\mathrm{K}$ & Age Mean & Mean age of study sample as a whole \\
\hline & $\mathrm{L}$ & Age SD & Standard deviation age of study sample as a whole \\
\hline & $\mathrm{M}$ & Baseline Total N & Total sample across all interventions measured at baseline \\
\hline & $\mathrm{N}$ & $\begin{array}{l}\text { Training Status } \\
\text { Description }\end{array}$ & Brief description of training status of study sample as a whole \\
\hline & $\mathrm{O}$ & Training Status Code & $1=$ Performance; 2 = Sporting; 3 = Other \\
\hline & $\mathrm{P}$ & Sex & Percentage female of study sample as a whole \\
\hline & Q & BMI Mean & Mean BMI of study sample as a whole \\
\hline & $\mathrm{R}$ & BMI SD & Standard deviation of BMI of study sample as a whole \\
\hline & $\mathrm{S}$ & Symptom Severity Mean & Mean severity measure at baseline of study sample as a whole \\
\hline & $\mathrm{T}$ & Symptom Severity SD & Standard deviation of severity measure at baseline of study sample as a whole \\
\hline & $\mathrm{U}$ & $\begin{array}{l}\text { Symptom Duration } \\
\text { Mean (Months) }\end{array}$ & Mean symptom duration reported in months \\
\hline & $\mathrm{V}$ & $\begin{array}{l}\text { Symptom Duration SD } \\
\text { (Months) }\end{array}$ & Standard deviation symptom duration reported in months \\
\hline & $\mathrm{W}$ & Population Comments & $\begin{array}{c}\text { Any additional information relevant to the participants investigated including } \\
\text { diagnostic criteria }\end{array}$ \\
\hline \multirow{4}{*}{ 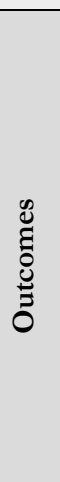 } & $\mathrm{X}$ & Outcome Category & $\begin{array}{c}1=\text { Disability; } 2 \text { = Pain on loading/activity; } 3=\text { Pain over a specified time; } 4= \\
\text { Pain without further specification; } 5=\text { Physical function capacity; } 6=\text { Patient } \\
\text { rating overall condition; 7) Participation; 8) Quality of life; 9) Adverse } \\
\text { effects/events; 10) Range of motion }\end{array}$ \\
\hline & & Outcome Tool & Description of outcome tool \\
\hline & $\mathrm{Z}$ & Reflection & $\begin{array}{c}1=\text { Increase in outcome indicates positive treatment; }-1=\text { Decrease in outcome } \\
\text { indicates positive treatment }\end{array}$ \\
\hline & $\mathrm{AA}$ & $\begin{array}{l}\text { Measurement Time } \\
\text { (Weeks) }\end{array}$ & Time of measurement in weeks \\
\hline \multirow{6}{*}{ 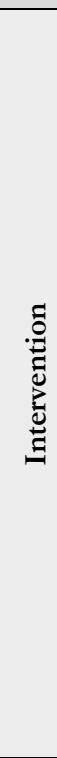 } & $\mathrm{AB}$ & $\begin{array}{l}\text { Dominant Broad } \\
\text { Treatment Class }\end{array}$ & $\begin{array}{l}\text { Only one dominant theme to be selected } \\
1=\text { Exercise; } 2=\text { Non-active; } 3=\text { Electro-therapy; } 4=\text { Biomechanics; } 5= \\
\text { Manual Therapy; } 6=\text { Injection Therapy; } 7=\text { Surgery }\end{array}$ \\
\hline & $\mathrm{AC}$ & $\begin{array}{l}\text { Total Broad Treatment } \\
\text { class }\end{array}$ & $\begin{array}{l}\text { Multiple themes to be selected as required } \\
1=\text { Exercise; } 2=\text { Non-active; } 3=\text { Electro-therapy; } 4=\text { Biomechanics; } 5= \\
\text { Manual Therapy; } 6=\text { Injection Therapy; } 7=\text { Surgery }\end{array}$ \\
\hline & $\mathrm{AD}$ & $\begin{array}{l}\text { Dominant Specific } \\
\text { Treatment Class }\end{array}$ & 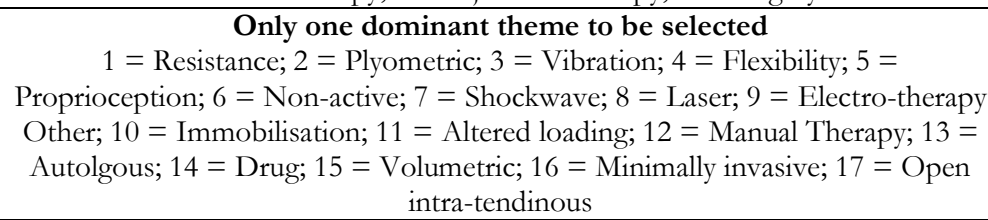 \\
\hline & $\mathrm{AE}$ & $\begin{array}{l}\text { Total Specific } \\
\text { Treatment Class }\end{array}$ & 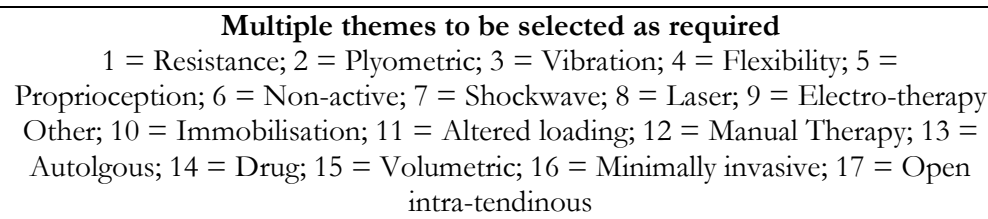 \\
\hline & $\mathrm{AF}$ & Intervention $\mathrm{N}$ & $\begin{array}{l}\text { Intervention sample size at specified time } \\
\end{array}$ \\
\hline & AG & $\begin{array}{l}\text { Intervention Total } \\
\text { Duration }\end{array}$ & Total duration of exercise intervention in weeks \\
\hline
\end{tabular}

Swinton, Shim, Pavlova, Moss, Maclean, Greig, Parkinson, Morrissey, Alexander, Cooper (2021) 
10.31236/osf.io/mx5pv | SportsR $x$ iv Preprint version 1

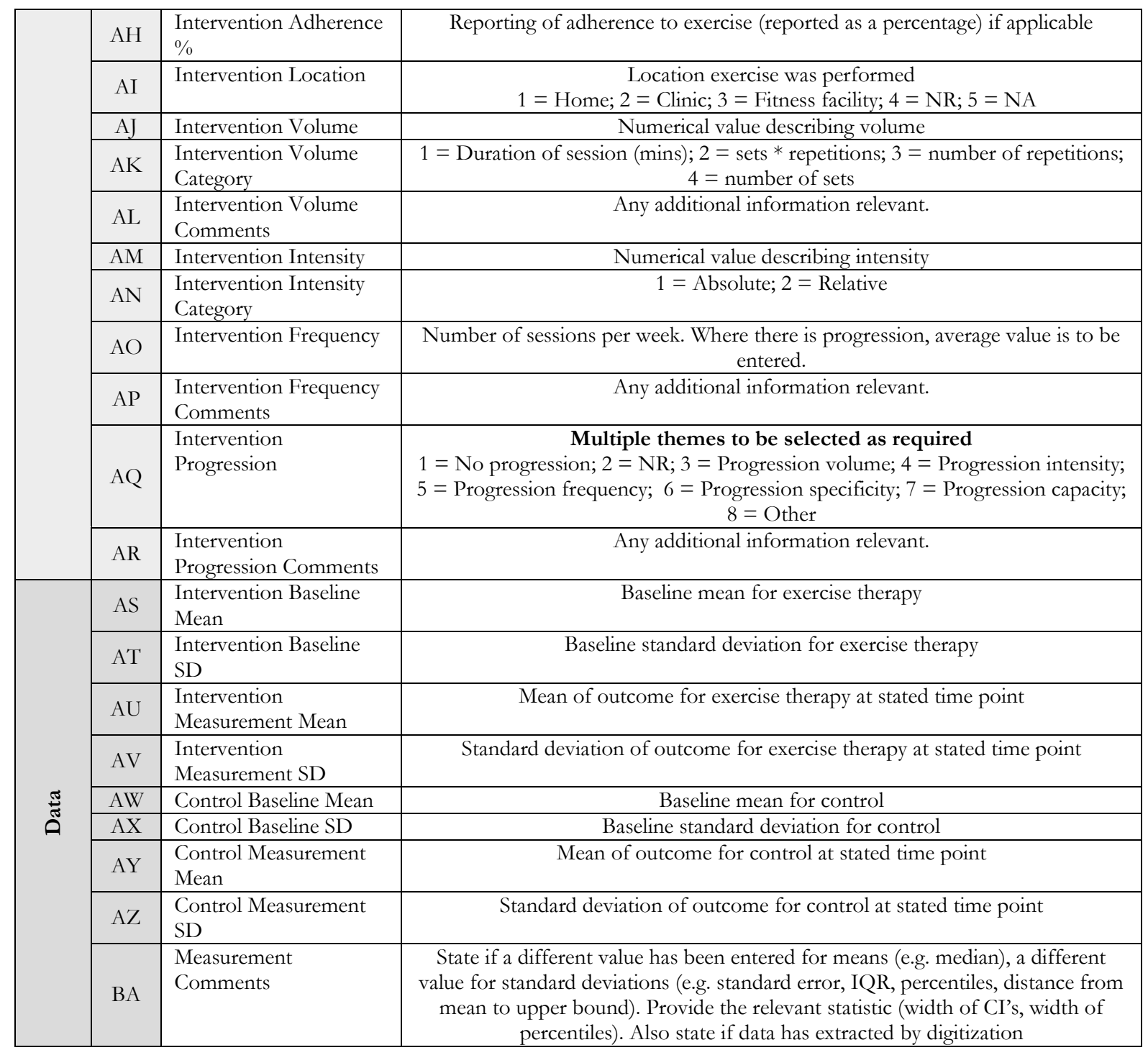

* Outcome Specific 